\title{
INCREASED LEVELS OF DEOXYRIBONUCLEIC ACID DURING TROPHOBLAST GIANT-CELL FORMATION IN MICE
}

\author{
C. V. HUNT AND G. B. AVERY \\ Department of Embryology, Clinical Research Center, \\ Children's Hospital of D.C. Research Foundation, \\ Washington, D.C. 20009, U.S.A.
}

(Received 22nd Fune 1970)

\begin{abstract}
Summary. Trophoblast grafts were disrupted 5, 8 and 10 days after the transplantation of $3 \frac{1}{2}$-day-old fertilized mouse ova beneath the kidney capsule of syngeneic mouse recipients. Gell suspensions or teased preparations of these grafts were stained with the Feulgen technique for deoxyribonucleic acid (DNA). The results of cytophotometric measurements of Feulgen-DNA in individual cell nuclei showed that between 5 and 10 days after grafting, the trophoblast nuclei exhibited massive increases in Feulgen-DNA. Although possible stoichiometric artifacts could not be completely excluded, the results indicated that trophoblast giant-cell formation does involve large increases in nuclear DNA.
\end{abstract}

\section{INTRODUCTION}

A characteristic observation of trophoblast giant cells in the rodent has been the complete absence of any indication of mitotic activity, even though mitotic figures are prevalent in early non-giant trophoblast cells (Alden, 1948; Bridgman, 1948; Dickson \& Bulmer, 1960). A number of studies have been published concerning the deoxyribonucleic acid (DNA) synthesis in the developing mouse and rat embryo (Atlas, Bond \& Cronkite, 1960; Jollie, 1964; Saccoman, Morgan \& Wells, 1967). These investigations have indicated that the trophoblast giant cells found in the developing placenta and surrounding the early conceptus exhibit labelling with tritiated thymidine during the early part of the gestational period, despite the apparent absence of mitotic figures.

Fawcett (1950) and others have demonstrated that fertilized ova transplanted beneath the kidney capsule will give relatively pure growths of trophoblast which progress from small dividing cells to large non-dividing giant cells which can have nuclear diameters of 80 to $100 \mu$. Using this system, Avery \& Hunt (1969) found that trophoblast giant-cell nuclei showed a highly positive Feulgen reaction, suggesting the presence of large amounts of DNA. In the present investigation, blastocysts were transplanted beneath the kidney capsule to study increases in trophoblast nuclear DNA during giant-cell transformation, using the technique of cytophotometric analysis of Feulgen-stained nuclei. 


\section{METHODS AND MATERIALS}

Inbred DBA/2 mice were obtained from Jackson Laboratories, Bar Harbor, Main, and from Microbiological Associates, Walkersville, Maryland. Females were mated with males late in the afternoon and were checked for copulation plugs the following morning. The presence of such a plug was taken to indicate Day 0 of pregnancy.

The blastocysts were flushed from the uterine horn $3 \frac{1}{2}$ days later with phosphate-buffered saline and transplanted under the kidney capsules of syngeneic adult female mice, one or two ova per kidney, using a technique similar to that described by Kirby (1962).

Kidney capsule grafts were disrupted 5, 8 and 10 days after grafting. The trophoblast tissue was separated from the kidney bed and the capsule and placed in calcium- and-magnesium-free phosphate-buffered saline. Separation of the graft from the bed can be accomplished with minimal contamination of the trophoblast with kidney cells. No attempt was made to separate the trophoblast from minor amounts of kidney-bed tissue or from non-trophoblastic embryoniccell types occasionally present in kidney-capsule-ova grafts. These cells are morphologically distinguishable from trophoblast nuclei after Feulgen staining.

To compare trophoblast Feulgen-DNA values with other tissues known to have diploid or polyploid Feulgen-DNA values, pieces of kidney and liver tissue were also removed from DBA/2 female mice.

All tissues were cut into $1-\mathrm{mm}$ cubes and placed in $0.25 \%$ trypsin (Difco $1: 250)$ at $38^{\circ} \mathbf{G}$ for $15 \mathrm{~min}$. They were then either prepared as a cell suspension in phosphate-buffered saline and a smear made on a microscope slide, or the cubes were placed on a microscope slide with a drop of phosphate-buffered saline and extensively teased with iridectomy knives.

All slides were air dried and after fixing in Carnoy's solution for $30 \mathrm{~min}$, the cells were hydrolysed in $\mathrm{N}-\mathrm{HGl}$ at $60^{\circ} \mathrm{C}$ for $10 \mathrm{~min}$, placed in Schiff's solution, prepared by the method of Tomasi (Pearse, 1960), for $1 \mathrm{hr}$, and mounted in Permount. Several slides of kidney, liver and trophoblast cells were used as unhydrolysed controls for the Feulgen reaction.

Cytophotometry involved the use of a Canalco ultramicrospectrophotometer and grating monochrometer. The Feulgen-DNA of individual cell nuclei was measured by the two-wavelength method (Pollister \& Ornstein, 1959).

\section{RESULTS}

All unhydrolysed controls for the Feulgen reaction were found to be negative for Feulgen staining.

The results of Feulgen-DNA measurements of fifty kidney nuclei from a cell suspension and fifty liver nuclei from a teased preparation are summarized in Text-figs. 1A and 1B. It can be seen that the kidney nuclei exhibited the expected unimodal distribution. This was interpreted as indicating that the diploid Feulgen-DNA value for DBA/2 cells was 2 to 4 arbitrary units of Feulgen-DNA. The liver nuclei exhibited the expected trimodal distribution reflecting the polyploid karyotype of some of these cells. 
The combined results of Feulgen-DNA measurements of two-hundred 5-day kidney-capsule-graft trophoblast nuclei are summarized in Text-figs. $1 \mathrm{C}$ and 2A. Determinations were made on two preparations of pooled teased material and on a cell suspension of pooled grafts.

Text-fig. 2B summarizes the combined results of Feulgen-DNA measurements of 112 8-day trophoblast-cell nuclei. Determinations were made on two preparations of teased grafts.

The combined results of Feulgen-DNA determinations on 108 10-day kidney-capsule-graft trophoblast nuclei are summarized in Text-fig. $2 \mathrm{C}$. Determinations were made on two preparations of teased grafts.

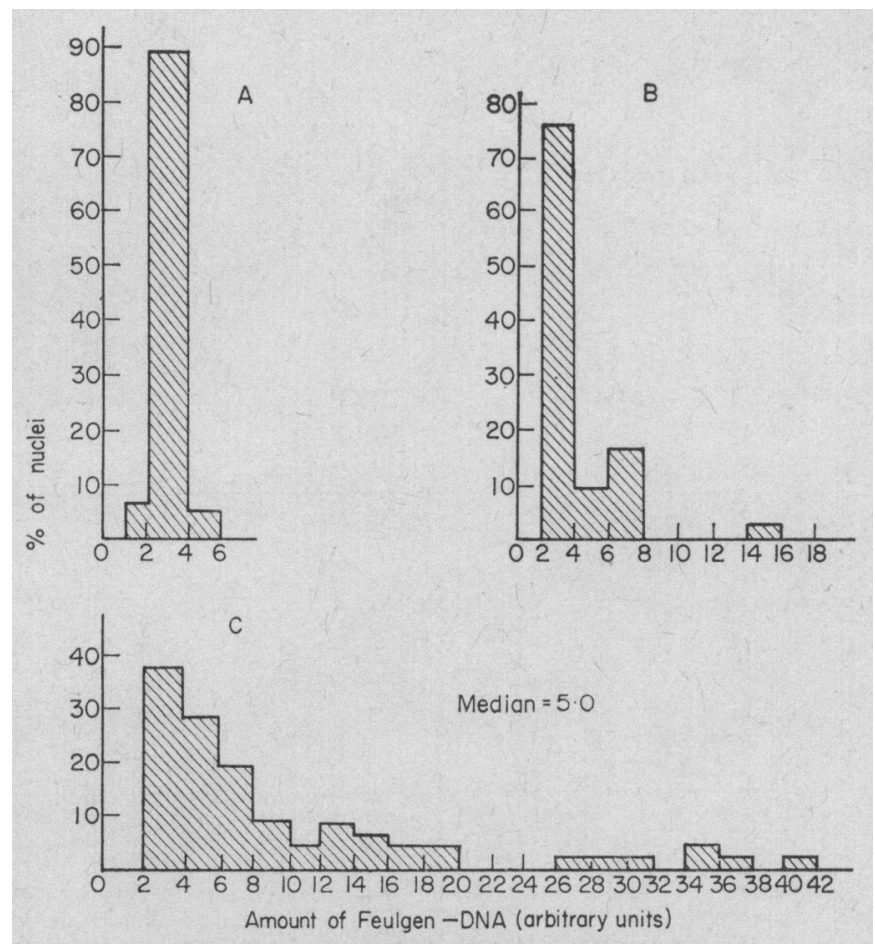

TExT-FIG. 1. Histograms showing the results of Feulgen-DNA measurements (in arbitrary units) of: A, fifty kidney-cell nuclei; B, fifty liver-cell nuclei; C, 200 trophoblast-cell nuclei disrupted 5 days after being grafted to the kidney capsule.

A wide range of nuclear sizes was found in both the 8- and 10-day trophoblast preparations. A sampling of the nuclear sizes found in these preparations was obtained by measuring the diameters of 100 nuclei on each slide. The frequency distributions of these measurements were then used to select nuclei for FeulgenDNA measurements in approximately the same proportion as nuclei of that diameter occurred in the preparation as a whole. Thus, a representative sampling of nuclei of each diameter class was measured microspectrophotometrically.

It can be seen in Text-fig. IC that the Feulgen-DNA values for the trophoblast nuclei 5 days after grafting exhibited a broad range when compared with kidney 
and liver-cell nuclei (Text-figs. 1A and 1B). However, this wide range in magnitude at 5 days is small when compared to the tremendous increases in trophoblast Feulgen-DNA values found 8 and 10 days after grafting (Text-figs. $2 \mathrm{~A}, 2 \mathrm{~B}$ and $2 \mathrm{G}$ ). At 10 days, some trophoblast nuclei were found to contain 800 to 900 arbitrary units of Feulgen-DNA. This represents a twenty-fold increase over the largest amounts found in 5-day trophoblast nuclei and 300 times the kidney-cell diploid Feulgen-DNA value. As indicated by the medians for 5, 8 and 10 days (Text-figs. 2A, 2B and 2G), the greatest change in FeulgenDNA took place between 5 and 8 days after grafting. During this period, there was a tremendous upward shift in Feulgen-DNA values.

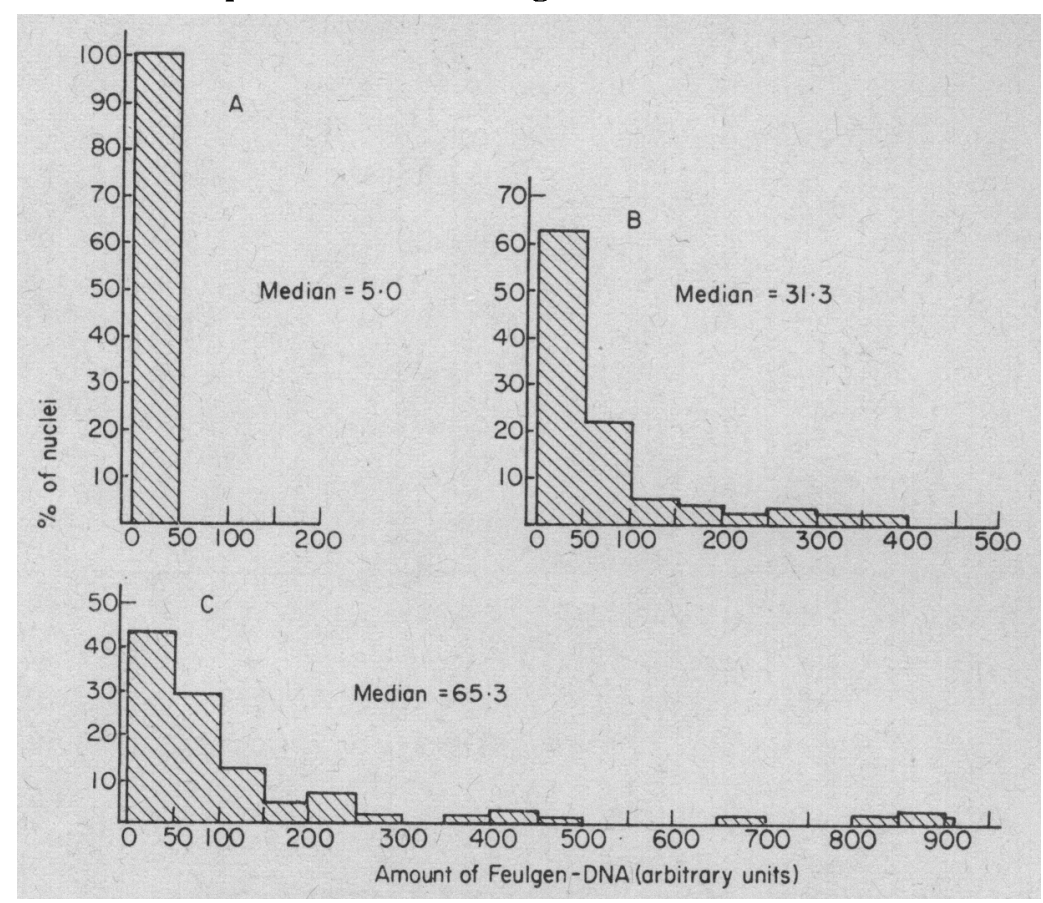

TEXT-RIG. 2. Histograms showing the results of Feulgen-DNA measurements (in arbitrary units) of: A, 5-day trophoblast nuclei from Text-fig. $1 \mathrm{C}$ on an abscissa scale with larger class intervals; B, 112 trophoblast-cell nuclei disrupted 8 days after being grafted to the kidney capsule; $\mathrm{C}, 108$ trophoblast-cell nuclei disrupted 10 days after being grafted to the kidney capsule.

Text-figs. 3A, 3B and $3 \mathrm{C}$ represent the diameters of trophoblast nuclei on which Feulgen-DNA measurements were made 5, 8 and 10 days after grafting. It can be seen that, between 5 and 10 days, increasingly large nuclei were found. This general shift of nuclei to larger sizes would appear to parallel the increasing shift in magnitude found in Feulgen-DNA values. Spearman's rank-order correlation (Mainland, 1963) between nuclear area and the amount of Feulgen-DNA gave coefficients of 0.843 for 5-day, 0.938 for 8-day, and 0.915 for 10-day trophoblast nuclei. These coefficients were significantly different from zero at the $1 \%$ level. This was interpreted as indicating that the progressive increase in nuclear size was strongly correlated with the progressive increase in Feulgen-DNA values. 




TExT-FIG. 3. Histograms showing the nuclear diameter distributions of trophoblast cells from kidney-capsule grafts on which Feulgen-DNA measurements were made 5, 8 and 10 days after grafting. A, 200 5-day trophoblast nuclei; B, 112 8-day trophoblast nuclei; C, 108 10-day trophoblast nuclei.

\section{DISGUSSION}

The results of the present investigation have indicated that trophoblast-cell nuclei derived from the transplantation of fertilized mouse ova beneath the kidney capsule undergo tremendous increases in their Feulgen-DNA content between 5 and 10 days after grafting. Since the cytophotometric measurement of nuclear DNA using the Feulgen reaction does not directly measure biological DNA but rather a dye which is assumed to be binding stoichiometrically to biological DNA, the increases in Feulgen-DNA which were found could reflect a spurious cytochemical increase in DNA.

While the specificity of the Feulgen reaction for DNA would seem to be well established, it is possible that changes in the physical state of the deoxyribonucleic acid-protein complex could alter the assumed stoichiometric staining of the Feulgen reaction. Garcia (1969) has demonstrated that subjecting peripheral blood leucocytes to hypotonic media results in a 7 to $12 \%$ increase in Feulgen-DNA values. Gledhill, Gledhill, Rigler \& Ringertz (1966) found that spermiogenesis was accompanied by a $50 \%$ reduction in Feulgen-DNA values while ultraviolet absorption values did not change. It is therefore conceivable that associated with the increase in size of trophoblast nuclei, there is a cytochemical increase in Feulgen staining due to increases in dye binding. However, despite the fact that the results presented here do not permit an analysis of such an effect on trophoblast Feulgen values, the large magnitude of the FeulgenDNA found in many of the trophoblast nuclei would seem to exceed considerably the limits of spurious cytochemical increases in Feulgen staining.

Previous studies relating to the formation of trophoblast giant cells have indicated that this process is associated with a biological increase in DNA. In the rat and mouse (Jollie, 1964; Saccoman et al., 1967), the tritiated thymidine 
labelling of trophoblast giant-cell nuclei suggested active DNA synthesis. However, since mitosis did not appear to follow, it was inferred that these cells were undergoing chromosomal replication and consequently becoming 'polyploid.'

Working with the rat and rabbit, Zybina (1961, 1964a) examined the hypertrophy of the trophoblast cell. Based on purely histological evidence, this investigator concluded that development of the trophoblast giant cell is the result of endomitotic polyploidization. Zybina (1964b) also made cytophotometric Feulgen-DNA measurements of the giant-cell nuclei found in the rat placenta. Assuming that the DNA content of a cell nucleus corresponds to the number of chromosomes present, Zybina attempted to determine the degree of polyploidy in these giant nuclei. He concluded that five classes of polyploidy were present, ranging between $64 \mathrm{n}$ and $1024 \mathrm{n}$. At 11.5 days gestational age, the Feulgen-DNA varied from $128 \mathrm{n}$ to $256 \mathrm{n}$, while at $17 \cdot 5$ days the majority of giant nuclei rose to $512 n$.

Other mechanisms of giant-cell formation have also been proposed. Galassi (1967) observed that the only embryonic cells to show labelling with tritiated thymidine after rat uteri were locally prelabelled were trophoblast giant cells. He concluded that the uterine epithelial and possibly the decidual cells contributed their nuclear material to the formation of giant-cell trophoblast by nuclear fusion. In kidney-capsule-graft studies, Avery \& Hunt (1969) found that trophoblast giant cells showed nuclear uptake of tritiated thymidine from host kidney-cell nuclei which had been systemically prelabelled before grafting. A number of investigators (Jollie, 1964; Schlesinger \& Koren, 1967; Saccoman et al., 1967; Avery \& Hunt, 1969) have suggested that trophoblast giant-cell nuclei are formed by fusion of adjacent trophoblast cells. While fusion is compatible with the morphological appearance of multinucleated trophoblast cells, direct experimental evidence to support this hypothesis is lacking.

The evidence presented in this paper indicates that trophoblast giant-cell formation apparently does involve a large increase in biological DNA as indicated by the manifold increase in Feulgen-DNA per nucleus. However, the present study does not permit a critical judgement between the possible modes of trophoblast giant-cell transformation.

\section{ACKNOWLEDGMENTS}

This paper includes work from a thesis presented by Carl V. Hunt to the faculty of the Department of Anatomy, Georgetown University, in partial fulfilment of the requirements for the degree of Master of Science.

Supported by grants FR-00284 of the NIH and GB-7076 of the National Science Foundation.

\section{REFERENGES}

ALDEN, R. H. (1948) Implantation of the rat egg. III. Origin and development of primary trophoblast giant cells. Am. F. Anat. 83, 143.

Atlas, M., Bond, V. P. \& Cronkrte, E. (1960) Deoxyribonucleic acid synthesis in the developing mouse embryo studied with tritiated thymidine. 7. Histochem. Cytochem. 8, 171. 
Avery, G. B. \& Hunt, C. V. (1969) The differentiation of trophoblast giant cells in the mouse, studied in kidney capsule grafts. Transplantn Proc. 1, 61.

Bridgman, J. (1948) A morphological study of the development of the placenta of the rat. II. An histochemical and cytochemical study of the development of the chorioallantoic placenta of the white rat. F. Morph. 83, 195.

Dickson, A. D. \& Bulmer, D. (1960) Observations on the placental giant cells of the rat. F. Anat. 94, 418.

FAwCETT, D. W. (1950) The development of mouse ova under the capsule of the kidney. Anat. Rec. 108, 71.

GaLASsI, L. (1967) Reutilization of maternal nuclear material by embryonic and trophoblastic cells in the rat for the synthesis of deoxyribonucleic acid. F. Histochem. Cytochem. 15, 573.

Garcia, A. M. (1969) Studies on deoxyribonucleic acid in leukocytes and related cells of mammals. VI. The Feulgen-deoxyribonucleic acid content of rabbit leukocytes after hypotonic treatment. 7. Histochem. Cytochem. 17, 47.

Gledhill, B. L., Gledhill, M. P., Rigler, R., JR \& Ringertz, N. R. (1966) Changes in deoxyribonucleoprotein during spermiogenesis in the bull. Expl Cell Res. 41, 652.

JoL.LE, W. P. (1964) Radioautographic observations on variations in deoxyribonucleic acid synthesis in the rat placenta with increasing gestational age. Am. F. Anat. 114, 161.

KIRBY, D. R. S. (1962) The influence of the uterine environment on the development of mouse eggs. 7. Embryol. exp. Morph. 10, 496.

Mainland, D. (1963) Elementary medical statistics. Saunders, Philadelphia.

Pearse, A. G. (1960) Histochemistry. Little Brown, Boston.

Pollister, A. W. \& OrNstein, L. (1959) The photometric chemical analysis of cells. In: Analytical Cytology, 2nd edn, p. 431. Ed. R. C. Mellors. McGraw-Hill, New York.

Saccoman, F. M., Morgan, C. F. \& Wells, L. J. (1967) Radioautographic studies of DNA synthesis in the developing extraembryonic membranes of the mouse. Anat. Rec. 158, 197.

Schlesinger, M. \& Koren, Z. (1967) Mouse trophoblastic cells in tissue culture. Fert. Steril. 18, 95.

Zxbina, E. V. (1961) Endomitosis and polyteny of the giant cells of trophoblast. Dokl. Acad. Nauk SSSR, 140, 1177. (Transl. of Dokl. Acad. Sci. U.S.S.R. (Biological Sci. Sections), 140, 797.)

ZyBrina, E. V. (1964a) Sex chromatin in giant cells of trophoblast and in cells of early rabbit embryo. Fedn Proc. Fedn Am. Socs exp. Biol. (Transl. Suppl.) 24, 868.

ZyBina, E. V. (1964b) Cytophotometric determinations of DNA content in nuclei of trophoblast giant cells. Dokl. Acad. Nauk SSSR, 153, 1428. (Transi. Dokl. Acad.Sci.U.S.S.R. (Biological Sci. Sections), 153, 1512.) 